REVISTA ARA Nº. VOLUME 9. PRIMAVERA+VERÃO 2020 • GRUPO MUSEU/PATRIMÔNIO FAU-USP

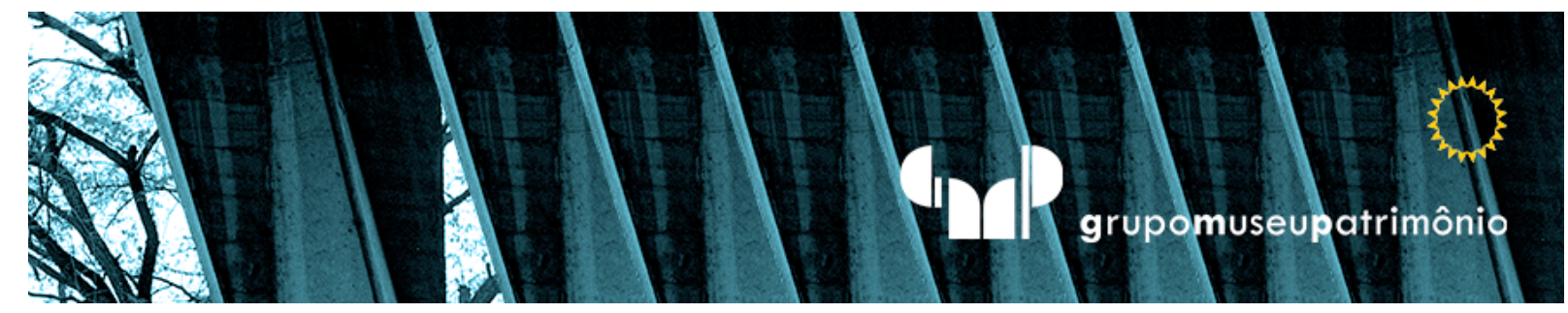

\title{
As coisas como elas são
}

\author{
Las cosas como son
}

Things as they are

Tuca Vieira ${ }^{1}$

Universidade de São Paulo, Faculdade de Arquitetura e Urbanismo, São Paulo,Brasil.tuca@tucavieira.com.br

\footnotetext{
${ }^{1}$ Pseudônimo de Luiz Arthur Leitão Vieira.
} 


\section{Resumo}

Este artigo examina novas formas de representação fotográfica no início do século XXI. A partir do texto de Walter Benjamin, em que diferencia as obras com "valor de culto" e "valor de exposição", analisa diferenças entre a fotografia de base química (dita analógica) e a fotografia digital. Por fim, analisa a proposta de representação da realidade contemporânea no trabalho de Andreas Gursky.

Palavras-Chave: Fotografia. Tecnologia. Representação. Arte. Capitalismo.

\section{Resumen}

Este artículo examina nuevas formas de representación fotográfica a principios del siglo XXI. Basado en el texto de Walter Benjamin, en el que diferencia los trabajos con "valor de culto" y "valor de exposición", analiza las diferencias entre la fotografía de base química (Ilamada analógica) y la fotografía digital. Finalmente, analiza la propuesta de representación de la realidad contemporánea en el trabajo de Andreas Gursky.

Palavras-Clave: Fotografía. Tecnología. Representación. Arte. Capitalismo

\section{Abstract}

This article examines new forms of photographic representation in the early 21st century. Based on Walter Benjamin's text, in which he differentiates works with "cult value" and "exposure value", it analyzes differences between chemical-based photography (so-called analog) and digital photography. Finally, it analyzes the proposal to represent contemporary reality in the work of Andreas Gursky.

Keywords: Photography. Technology. Representation. Art. Capitalism. 


\section{As COISAS COMO ELAS SÃO}

magine ser por um instante um laboratorista que precisa fazer uma cópia

de uma fotografia muito famosa. Imagine ter em mãos, por exemplo, o negativo de Atrás da Estação St. Lazare (1932), de Henri Cartier-Bresson ou Guerrilheiro heroico (o célebre retrato de Che Guevara, de 1960), de Alberto Korda, ou uma das grandes placas de vidro que Marc Ferrez utilizou para retratar o Rio de Janeiro. Imagine ver esses objetos translúcidos através de uma lupa, pousados sobre uma mesa de luz. Basta tocá-los para perceber que se trata de algo extremamente delicado e precioso (Fig. 1).

O negativo é esse belíssimo objeto que, junto com o fotógrafo e a câmera, "esteve lá", diante da cena. Uma vez exposto à luz, teve sua estrutura físico-

\footnotetext{
${ }^{2}$ Este artigo foi escrito a partir da defesa da dissertação de mestrado intitulada Salto no escuro estratégias artísticas de mapeamento cognitivo, defendida na Faculdade de Arquitetura e Urbanismo da Universidade de São Paulo, em 2018. Fizeram parte da banca, além do orientador Guilherme Wisnik (FAUUSP), os professores Ricardo N. Fabbrini (FFLCH-USP) e Nelson Brissac Peixoto (PUC-SP), aos quais agradeço pelas preciosas sugestões aqui incorporadas. Uma versão ampliada e revista da dissertação será publicada em forma de livro pela editora Hedra em 2020.
} 
química irreversivelmente transformada pela incidência direta dos raios luminosos refletidos pelo objeto fotografado. Por isso, a imagem captada com películas fotossensíveis ainda guarda uma relação indicial com aquilo que representa.

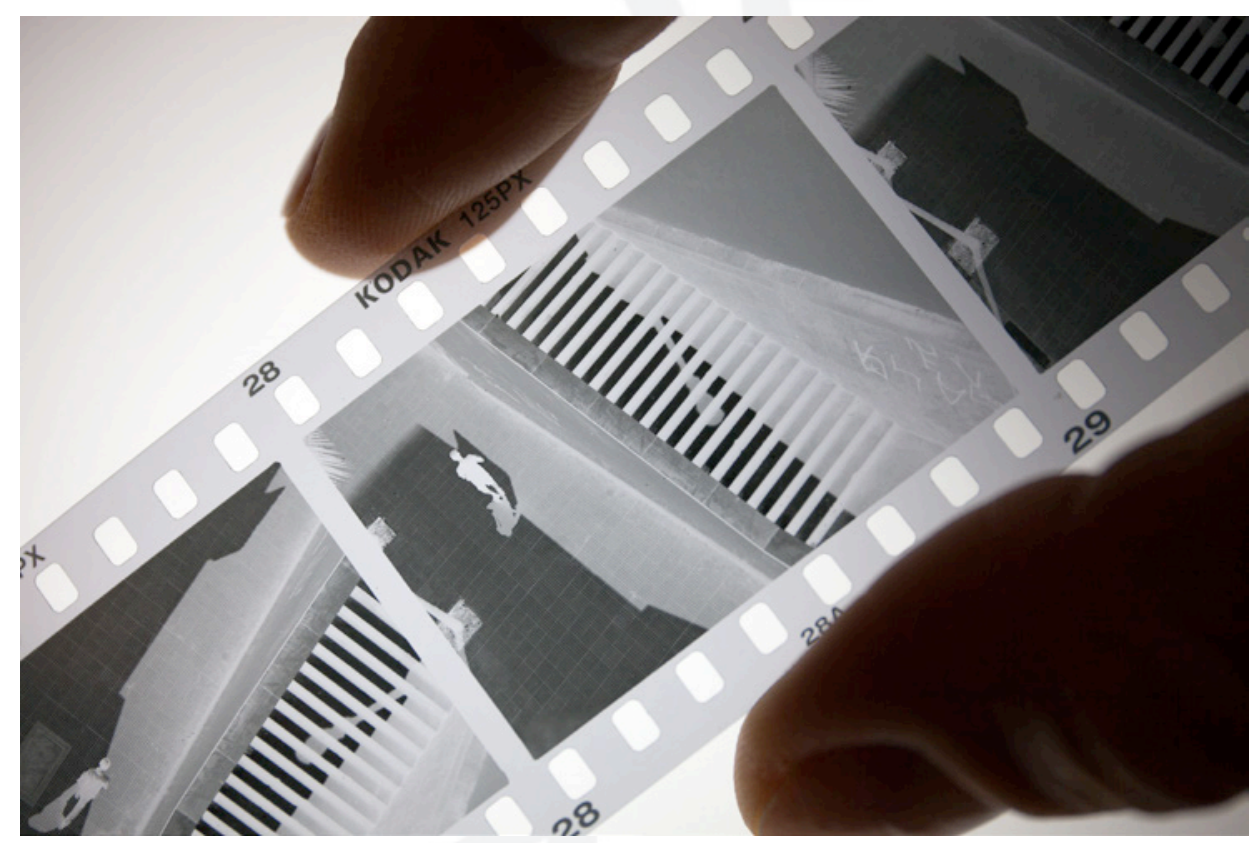

Figura 1: Tuca Vieira, 2020. Negativo da série "Fotografia de Rua" (2008).

É curioso pensar - a partir do célebre texto de Walter Benjamin, $A$ obra de arte na era de sua reprodutibilidade técnica (1935-36) - que a fotografia é sem dúvida o caso exemplar da obra de arte tecnicamente reprodutível mas, ao mesmo tempo, o filme fotográfico revelado (seja ele negativo ou diapositivo), é um objeto único e irreprodutível e, portanto, possuidor de "aura", essa qualidade simbólica que confere autenticidade e "valor de culto" a esses objetos. Segundo Benjamin (1985, p. 173), em oposição ao "valor de exposição", o mais importante em relação os objetos com valor de culto é que eles existam, e não necessariamente que sejam vistos. Assim é o negativo fotográfico, guardado em algum lugar seguro, manipulado raramente. 
E esse objeto não é exatamente como a matriz em madeira de uma gravura ou a fôrma de uma escultura. A película, constituída pela base plástica e pela emulsão química, mesmo após o processo de fixação, ainda reage lentamente à luz e envelhece. Há uma perda gradativa e irreversível da imagem que, aos poucos, vai "esmaecendo" e, um dia, desaparecerá para sempre. Ela é o suporte da própria imagem, como se a carregasse consigo. Se não pode ser chamado exatamente de fotografia "original", uma vez que ainda não se transformou plenamente numa forma de exibição, todas as informações visuais que depois veremos na fotografia final já estão ali ${ }^{3}$.

Pensemos, por exemplo, em The blue marble (a bola de gude azul), a mais famosa fotografia do planeta Terra (Fig. 2), realizada pelos astronautas a bordo da missão lunar Apolo 17, em 1972. A fotografia é creditada à tripulação da missão como um todo, e foi feita em película diapositiva com uma câmera Hasselblad especialmente modificada. Aquela foi a última vez que um ser humano se afastou da Terra a uma distância suficiente para poder enxergá-la por inteiro. Não há dúvida de que o diapositivo da Blue Marble, seguramente guardado pela NASA como um pequeno tesouro de valor incalculável, carrega consigo a "aura" de ser a materialização de uma das mais raras e belas imagens já vistas por um ser humano.

Posteriormente, outras fotos da Terra foram realizadas por sondas, veículos não-tripulados ou a partir da fusão de várias imagens digitais. Inclusive há uma nova série dessas fotografias (também chamadas Blue Marble), que apresenta a Terra de uma maneira espetacular, mas impossível de ser vista com os próprios olhos. São dados transmitidas por satélite e manipulados posteriormente, num processo que escolhe o melhor fragmento de cada imagem captada, elimina nuvens indesejadas, realça cores e aumenta o contraste (além de colocar os Estados Unidos no centro da fotografia). São

\footnotetext{
${ }^{3}$ O fotógrafo norte-americano Ansel Adams comparava a fotografia com a música clássica - o negativo sendo a partitura e a cópia fotográfica, a interpretação. Assim, cada laboratorista poderia interpretar o negativo a sua maneira.
} 
muito mais nítidas e detalhadas do que a fotografia trazida pela Apollo 17, mas nenhuma delas é este objeto único que, de fato, "esteve lá".

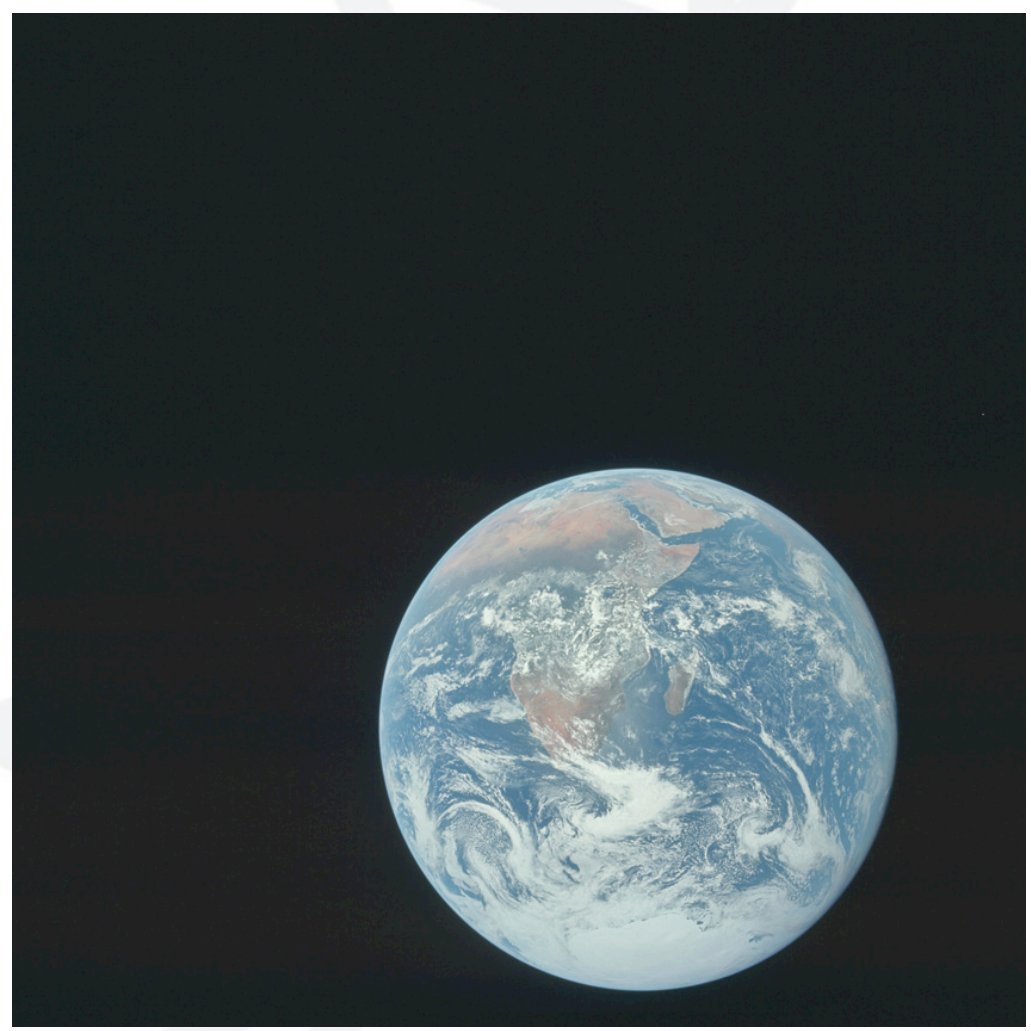

Figura 2: Apollo 17. The blue marble (1972). Versão original sem corte. Fonte: NASA.

Podemos entender o filme fotográfico como uma espécie de decalque da cena, como se a abertura do obturador da câmera permitisse que os elementos visuais imprimissem a si mesmos diretamente na película, sem a intervenção do fotógrafo. Na captura digital, diferentemente, a luz é convertida e codificada numa longa sequência numérica que depois precisa ser processada para se tornar imagem novamente, na tela do computador. Com isso, a relação indicial que o negativo representa deixa de existir.

Quero com isso salientar esse aspecto que foge ao texto de Benjamin: apesar da natureza essencialmente reprodutível da fotografia, ela ainda carregava 
algum aspecto "aurático", pela existência da matriz única em película, geralmente um negativo ${ }^{4}$. Agora, o equivalente digital da película, ou seja, o "arquivo" informático que registra a sequência numérica codificada, pode ser replicado, transmitido e armazenado, conservando sua integridade; pode ser usado indefinidamente para a impressão de novas cópias fotográficas sem qualquer perda de qualidade e (a não ser por um grande descuido ou por um catastrófico "apagamento" digital) existirá para sempre ${ }^{5}$. Mais ainda, conforme são introduzidos no mercado novos softwares e impressoras de tecnologia superior, as impressões no futuro serão melhores que as de hoje. Diferentemente do negativo, aqui há apenas "valor de exposição". Assim, com a codificação total da imagem digital, o prognóstico de Benjamin agora se realiza plenamente. As noções de autenticidade e originalidade que tinham sofrido um abalo com o advento das "imagens técnicas", agora acusam o golpe definitivo com a possibilidade de "reprodutibilidade total" 6 .

2

Podemos pensar também que o negativo, com sua natureza misteriosa e delicada, que esconde uma imagem a ser revelada, se aproxima de uma determinada ideia de erótico. Lembremos do laboratório fotográfico, esse ambiente escuro e silencioso, iluminado minimamente por luzes vermelhas e misteriosas, repleto de odores estranhos. Ali, o papel fotográfico passa por várias etapas, a partir da abertura da caixa onde repousa num envelope preto

\footnotetext{
${ }^{4}$ Os concursos de fotografia muitas vezes exigiam dos premiados a apresentacão do negativo como forma de provar tanto a autoria quanto a autenticidade da imagem. Hoje, mesmo que haja um arquivo "original" (chamado RAW, ou "cru") que contém todas as informações captadas na cena, as fotos digitais passam obrigatoriamente por um processo de "pós-produção" no software. Com isso, os concursos têm dificuldade para definir os limites da manipulação e, eventualmente, fraudes acontecem.

${ }^{5}$ Pessoalmente, sempre que faço uma simulação mental de um incêndio, perguntando-me o que salvaria em primeiro lugar, respondo: o arquivo de negativos.
}

${ }^{6}$ É sintomático que, ao mesmo tempo em que a fotografia chega na fase de "reprodutibilidade total", os fotógrafos-artistas passem a numerar suas fotos em séries limitadas - basicamente uma estratégia de mercado, na tentativa artificial de fazer da cópia fotográfica um objeto com "valor de culto". 
selado. Depois disso, é colocado na base do ampliador, esse aparelho que projeta a imagem do negativo na superfície do papel fotossensível. Exposto brevemente à luz que trespassa o negativo colocado delicadamente no aparelho, o material fotossensível que recobre o papel (a emulsão) sofre uma alteração em sua estrutura química, acusando as informações luminosas dadas pelo negativo. No entanto, ainda não há imagem para ser vista, pois ela está como se diz - em "estado latente", aguardando os banhos químicos que traduzirão essas informações luminosas em preto, branco e gradações de cinza, em relação oposta às tonalidades do negativo. Qualquer um que já tenha ampliado uma fotografia num laboratório fotográfico há de lembrar-se do momento em que a imagem sobre o papel, imerso na banheira do revelador, surge lentamente, como mágica.

Isso tudo remete a um universo sensível com o qual a fotografia digital não pode sonhar. O processamento digital se dá em ambiente anódino, limpo, controlado. Não há cheiro, não há tato, não há movimento corporal. Tudo é perfeitamente visível e codificado. A imagem acontece na tela, diante do sujeito sentado no computador, em simbiose corporal com a máquina, como se fosse parte dela. No universo digital não há lugar para nuances ou "zonas escuras". Seu ideal é o da clareza matemática, da redução da imagem a um código transmissível e veloz ${ }^{7}$. O digital é, portanto, obsceno e pornográfico, em sua busca da hipervisibilidade, daquilo que é "mais visível do que o visível", para usarmos os termos de Baudrillard (1996, p.49).

A tecnologia computacional da imagem chegou a tal ponto de sofisticação que, com alguma habilidade, é possível manipular quase que infinitamente a distribuição dos pixels e, consequentemente, dos objetos visuais. $\mathrm{O}$ antigo processo de montagem ou colagem, que cortava e colava as fotografias, passa agora a ser feito com precisão microscópica. A fotografia digitalizada passa a

\footnotetext{
${ }^{7}$ É interessante notar os termos em francês para fotografia analógica e fotografia digital: photographie argentique (fotografia argêntica, referindo-se à prata utilizada como principal material fotossensível na emulsão das películas) e photographie numérique (fotografia numérica).
} 
ser um monstruoso quebra-cabeças eletrônico composto por milhões de pecinhas, sendo possível interferir isoladamente em cada uma delas ${ }^{8}$. Essa espécie de "pictorialismo digital" resulta numa imagem fotográfica cujos acréscimos e supressões são imperceptíveis a olho nu - um procedimento que coloca em suspeição o próprio caráter da representação da fotografia e instaura permanentemente o problema da ética sobre o fazer fotográfico. Hoje, conscientes dessas infinitas possibilidades de transformação da imagem, aprendemos a desconfiar das fotografias.

Se, no fotojornalismo, essa facilidade de manipulação representa um problema ético real, nas mãos de um artista pode servir como ferramenta criativa. 0 fotógrafo alemão Andreas Gursky utiliza sofisticados softwares de edição de imagem para criar suas obras, manipulando pesadamente as fotografias, seja multiplicando os pontos de fuga e subvertendo as regras da perspectiva linear através de "colagens", quanto simplesmente acrescentando e eliminando elementos. O trabalho fotográfico de campo é apenas a primeira etapa do processo, apenas a captura das imagens na rua, para depois ser finalizada numa segunda etapa de "pós-produção" no computador.

Paris, Montparnasse (1993), por exemplo (Fig. 3), retrata o conjunto habitacional modernista projetado por Jean Dubuisson na capital francesa. É uma elevação arquitetônica resultada de duas fotografias realizadas separadamente, mostrando o edifício de uma maneira que não se pode ver in loco, pela falta de recuo necessário para captar toda a fachada numa única tomada. Com esse gesto de fusão (que depois será aprimorado em outros trabalhos), Gursky desobedece (como fazem outros tantos artistas) as regras da perspectiva linear, eliminando aquele ponto único no qual o sujeito se

\footnotetext{
${ }^{8}$ Uma câmera de 30 megapixel (relativamente comum nos dias de hoje) produz uma imagem com cerca de 30 milhões pixels ( 1 megapixel = 1 milhão de pixels). Cada um desses pixels tem a sua disposição 16.777.216 combinações diferentes de cor, tonalidade, saturação e brilho, utilizando-se o sistema de cores RGB (red, green blue), padrão da maioria dos softwares de processamento de imagem.
} 
coloca para ver o mundo como se olhasse através do buraco de uma fechadura, tão característico do Renascimento e da fotografia em geral.

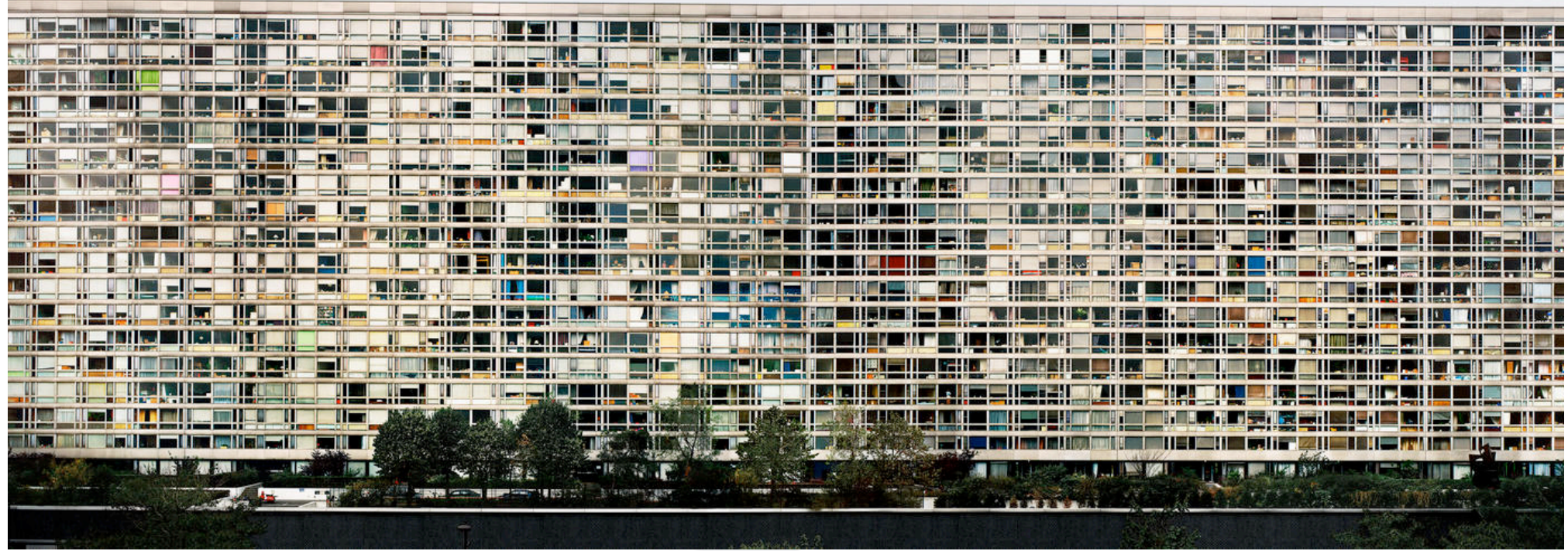

Figura 3: Andreas Gursky. Paris, Montparnasse (1993). Fonte: Site do autor.

Lembremos que a imagem capturada pela câmera escura, através da objetiva, e projetada na superfície fotossensível, normalmente apresenta as mesmas características geométricas de uma pintura criada a partir das regras da perspectiva linear. Esse sistema visual foi criado para superar a dificuldade de se representar realisticamente objetos tridimensionais numa superfície bidimensional e obteve tanto sucesso que acabou dominando a forma do Ocidente ver o mundo por mais de 500 anos. Tanto o ponto de fuga quanto a diminuição dos objetos conforme a distância - os principais elementos que criam a sensação de profundidade realística - são dados visuais produzidos pelas duas técnicas, uma vez que ambas supõem a existência de um único ponto de vista organizador da imagem. Mas com uma 
diferença fundamental: aquilo que, através da perspectiva, é produzido aplicando complicadas regras geométricas - num processo sofisticado e lento, que exige anos de treino por parte do artista - é realizado pela câmera fotográfica num instante. Em outras palavras, a câmera fotográfica é uma máquina automática de criação de perspectiva.

Gursky, no entanto, subverte essa vocação da fotografia e constrói um edifício de pura frontalidade, onde todas as janelas são vistas de frente, onde todos os pontos são pontos de fuga. O resultado é uma obra por um lado "fria", em acordo com a tendência "inexpressiva" da linhagem de fotógrafos alemães contemporâneos mas, por outro, aberta às complexidades que de fato experimentamos na tentativa de interpretar a realidade multifacetada em que vivemos.

Esse efeito é enfatizado ao experimentar a obra numa galeria ou museu. Com suas grandes dimensões, ela convida o observador a se deslocar horizontalmente, percorrendo com os olhos cada uma das janelas do bloco residencial. Se o casal Bernd e Hilla Becher, mestres de Gursky na chamada "escola de fotografia de Düsseldorf", criaram suas conhecidas "tipologias", fotografando diversas variantes de um mesmo tipo de edificação, e depois reunindo-as em grids expositivos, Gursky parece fazer o mesmo, mas numa única fotografia. Assim como no trabalho do casal alemão, esta obra de Gursky convida ao conhecimento por método de comparação ${ }^{9}$. Cada janela pode ser cotejada com as outras, todas iguais e diferentes ao mesmo tempo, representando as diversas pessoas que vivem ali. Se as diferenças remetem à individualidade de cada um dos moradores, a semelhança ressalta a padronização da vida contemporânea nas grandes cidades.

\footnotetext{
${ }^{9}$ Esse método, que tem origem no impulso classificatório e enciclopédico do século XVIII, é típico das ciências naturais, mais precisamente da botânica e da zoologia, em que as plantas do mesmo gênero ou animais da mesma espécie são agrupados a fim de serem comparados. Grandes viajantes-cientistas alemães, como Alexander von Humboldt (1769 - 1859), por exemplo, se empenharam nessa tarefa, sobretudo em países pouco explorados na época, como o Brasil.
} 
Andreas Gursky, Thomas Struth e Thomas Ruff (chamados de "struffsky" pelo jornal nova-iorquino Village Voice) estão entre os fotógrafos que levaram definitivamente a fotografia para o campo da arte contemporânea. Utilizandose de procedimentos como a fusão digital, a apropriação de imagens da ciência, o uso dos grandes formatos e de sofisticadas ferramentas da tecnologia digital, esses fotógrafos expandiram o horizonte da linguagem fotográfica, e colocaram a "técnica fria" a serviço do distanciamento emocional, da suposta objetividade e da aparente neutralidade. Aqui, segundo a crítica Charllotte Cotton (2010, p. 81), "a ênfase recai na fotografia como um modo de ir além das limitações da perspectiva individual, um modo de mapear a extensão de forças, invisíveis desde a perspectiva do indivíduo isolado, que regem o mundo natural e o mundo criado pelo homem".

Gursky, assim como seus colegas, acredita ser capaz de realizar uma representação "neutra" da realidade, desprovida de afeto e de opinião, como se mostrasse o mundo em toda sua verdade, objetivamente, sem intervenção da subjetividade humana: "eu mostro nosso mundo contemporâneo do jeito que ele é", diz, sem muita modéstia (NAYERI, 2018, trad. minha). A opinião pessoal é tudo aquilo que os fotógrafos dessa vertente procuram evitar a todo custo. É como se os objetos, lugares e situações pudessem falar por conta própria, cabendo ao artista apenas "mostrar". Se considerarmos que há basicamente dois tipos de artistas: aqueles que pretendem representar a realidade e aqueles que pretendem transformar a realidade, esses fotógrafos claramente se situam no primeiro grupo, mesmo que, para isso, tenham que lançar mão de imagens que não são verificáveis a olho nu.

Talvez possamos entender essa postura no contexto da Alemanha pós-guerra, um país derrotado dramaticamente e agora traumatizado e envergonhado por seus próprios feitos. Nesse contexto, a "neutralidade" pretendida pode ser tanto o resultado de uma busca legítima da verdade depois da vivência de tanta barbárie, como também o efeito de uma anestesia geral necessária como forma de esquecimento dessa mesma barbárie. 
Uma das primeiras descobertas de quem começa a fotografar seriamente é que a câmera, pelo menos tecnicamente, é capaz de enxergar mais do que o olho humano. Muitos detalhes de uma cena passam despercebidos pelo fotógrafo no momento da captura e são percebidos apenas após a ampliação fotográfica. E quanto maior é o tamanho do negativo ou a capacidade de "resolução" digital, mais detalhes são registrados ${ }^{10}$. Portanto, toda fotografia de grande formato (falo tanto da captura quanto da exibição) mostra mais do que somos capazes de ver naturalmente - um efeito que se torna ainda mais evidente quando a fotografia apresenta alta qualidade de impressão e é mostrada no ambiente controlado de uma galeria. Ali, podemos tomar todo o tempo necessário e, confortavelmente, examinar com os olhos a cena estática, congelada pela câmera, sem o risco de transformação temporal a que o mundo real está submetido. Este é o encanto de uma fotografia de Stephen Shore, por exemplo, com suas esquinas banais onde primeiramente nada é extraordinário, mas, com o tempo e o exame minucioso do olhar, os detalhes vão se revelando lentamente.

Gursky, com a manipulação digital, leva essa capacidade intrínseca da fotografia em grande formato a outro patamar. A alta definição das imagens, a saturação cromática, a monumentalidade física das obras, as tecnologias de impressão e montagem e, é claro, a excelência técnica do fotógrafo, acabam criando algo que às vezes parece "mais real do que o real". Trata-se de outra forma de falsificação da realidade, não mais a deficiência de uma "meia verdade", mas o excesso de "uma verdade e meia". Este hiper-realismo foi

\footnotetext{
${ }^{10}$ No filme Blow-up (1967), de Michelangelo Antonioni, o protagonista é um fotógrafo de moda que, ao ampliar seguidamente no laboratório uma fotografia que fez por acaso, percebe ter involuntariamente capturado a cena de um crime. O termo blow-up é usado em fotografia justamente para referir-se a ampliações excessivas, que "explodem" os detalhes e revelam a própria estrutura (grãos ou pixels) da fotografia. Em Blade Runner (1982), de Ridley Scott, há uma cena semelhante, talvez em homenagem ao filme de Antonioni. O detetive Deckard utiliza uma máquina sofisticada de ampliação para detectar um detalhe escondido numa fotografia. A "máquina Esper" do filme, semelhante a um computador, pode ser entendida como o equivalente pós-moderno e digital do laboratório químico de Blow-up e prefigura, de certo modo, as ferramentas cartográficas digitais como o Google Earth.
} 
definido por Baudrillard como uma simulação de um real que nunca existiu, e que acaba substituindo e anulando a própria realidade com seu poder de sedução $^{11}$. É um fenômeno definidor da sociedade de consumo pós-moderna e um modo de ver que se alinha às telas de alta definição, às plataformas cartográficas digitais, ao universo da publicidade e ao próprio acesso à informação em época de comunicações em rede. Nesse sentido, Gursky provavelmente preferiria a Blue Marble de 2012 (Fig. 4), digitalizada, manipulada e supernítida, que mostra o globo terrestre idealizado, sem as imperfeições e o acaso da fotografia de 1972.

Mas todo esse hiper-realismo não significa necessariamente acesso a um mundo de verdades. De fato, talvez esteja mais próximo a um novo tipo de cegueira. Não se trata mais de uma fotografia subexposta que esconde os elementos na escuridão, mas de uma fotografia superexposta, que cega por excesso de claridade. Pois há, como nos revela o crítico Guilherme Wisnik (2018, p. 87), uma estranha relação entre nitidez e opacidade - duas qualidades que, embora aparentemente antagônicas, podem servir a propósitos trocados. Assim como o mistério e a dúvida podem ser iluminadores da verdade na medida em que representam as imperfeições de nosso mundo imperfeito, muitas vezes o excesso de nitidez, por seu poder inebriante e sedutor, tem como efeito a ocultação dessa mesma verdade. Um mundo destituído de ambiguidades, sem texturas nem desfoques, que se mostra como "perfeito", impede a própria ação do sujeito que tenta transformá-lo, restando a ele apenas uma "leitura passiva dos seus códigos de funcionamento" (WISNIK, 2012, p. 33). No fundo, este é o mesmo problema que existe na confusão entre informação e conhecimento num mundo onde a

\footnotetext{
${ }^{11}$ Hiper-realismo é também um movimento artístico que tem origem no anos 1960, tributário da Pop Art e do Fotorrealismo. Enquanto esse último criava grandes pinturas a partir de fotografias reproduzidas minuciosamente na tela, o Hiper-realismo se manifesta sobretudo na escultura, criando figuras tão verossímeis que parecem vivas (como no trabalho do australiano Ron Mueck, por exemplo). No fundo essas obras não são exatamente realistas, pois não representam o mundo como vemos, mas uma fotografia desse mundo. São representações de representações. Apesar da impressionante sofisticação técnica, parece-me mais um exercício formal de forte apelo midiático. $\mathrm{O}$ movimento é considerado por alguns como a última das vanguardas históricas do século XX.
} 
informação, através da internet, parece estar "ao alcance dos dedos" - uma das grandes ilusões de nosso tempo.

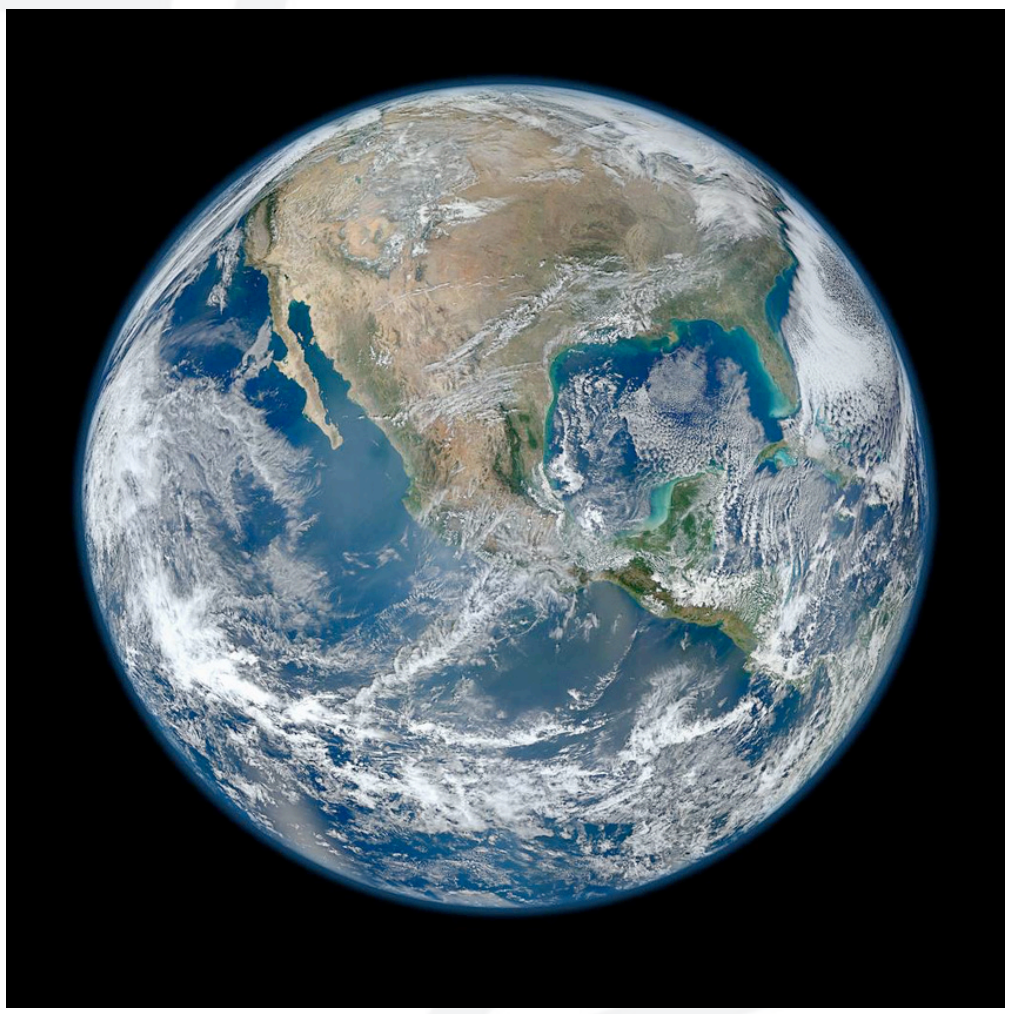

Figura 4: NASA. The blue marble (2012). Fonte: NASA.

O interesse na obra de Gursky repousa em sua hábil elaboração artística do hiper-realismo, como se dissesse que o olhar nu e cru não basta, que a realidade complexa em que vivemos não se dá a ver tão facilmente, escondida para além de nossa capacidade de apreensão visual ocular. A realidade, na proposta de Gursky, estaria mais próxima daquilo que não vemos do que daquilo que vemos. E, se nem o olho nem a câmera fotográfica é capaz de enxergá-la, será preciso criá-la. Assim, paradoxalmente, o artifício é usado para restaurar a verdade, para nos aproximar de uma realidade impalpável e invisível. A máxima que diz "é preciso ver para crer", que atribui aos olhos a legitimidade última da verdade, aqui é invertida, tornando-se "é preciso crer 
para ver" pois, aceitando as imagens de Gursky, o mundo complexo e globalizado em que vivemos se tornaria um pouco mais claro.

Pela pretensão, pelas dimensões das obras e pela tradição acadêmica alemã podemos abordar o trabalho de Gursky pela via da categoria estética do sublime. De Aristóteles a Lyotard, passando por Kant e Hegel, o sublime referese a uma beleza grandiosa, assombrosa e desmesurada, que ultrapassa a capacidade humana de apreensão direta e não pode ser totalmente compreendida. É uma beleza que flerta com o trágico e com o divino, que impõe uma força de cima para baixo, ameaçando a fragilidade humana. Dessa forma, o sublime pode tanto esmagar o sujeito, impedindo qualquer tentativa de relação entre o homem e essa força assombrosa, quanto incitar enormemente a imaginação, levada ao limite na tentativa de compreender esses fenômenos que escapam à apreensão humana. Pode ser, portanto, um proposta estética válida na tentativa de "representar o irrepresentável" pois implica, por natureza, uma inadequação, um "fracasso representacional" que pode ser bastante útil para a análise da realidade contemporânea, caracterizada pelo descompasso relacional resultante do abismo entre a experiência humana imediata e as grandes instâncias que de fato regem nossas vidas, conforme percebidos por diversos pensadores como Fredric Jameson, Paulo Virilio e Zygmunt Bauman.

A obra de Andreas Gursky flerta com esse sublime tanto nos temas retratados quanto na própria forma de apresentação das imagens fotográficas. Ele retratou grandes aglomerações humanas, paisagens grandiosas, obras de infraestrutura, grandes edifícios e uma série de espaços ligados ao mundo financeiro, ao entretenimento, aos esportes, aos serviços e ao comércio de um mundo interconectado. As fotografias em grandes dimensões (graças aos avanços das técnicas de impressão digital) e a exibição das obras isoladas nas grandes paredes dos museus e galerias impressionam pela monumentalidade e pela própria presença física das molduras. Nesses ambientes, acabam concorrendo diretamente com as pinturas de grande formato, remetendo às grandes paisagens ou batalhas na tradição da pintura europeia. É evidente 
uma influência do romantismo alemão, com seus personagens pequenos e frágeis diante da imensidão das paisagens naturais, como nas pinturas de Caspar Wolf (1735-1783) e de Caspar David Friedrich (1774-1840).

O exagero e a desmedida próprias do sublime são usados não apenas para mostrar a fragilidade do homem diante da força da natureza ou das instâncias de poder que regem nossas vidas, mas também podem servir como ferramenta crítica que, através da inverosimilhança e do absurdo acabam por revelar a artificialidade de um mundo regido pelo consumo e pela publicidade que, no entanto, exerce grande fascínio. Dessa forma, a obra de Gursky estaria representando aquilo que o filósofo brasileiro Vladimir Safatle $(2007$, p. 53) chamou de "sublime capitalista", uma imagem do grande universo do capital e de nossa sociedade competitiva, consumista e conectada deste início de século XXI em seu "funcionamento perfeito", com todo este aparato ao mesmo tempo sedutor e opressor.

A lógica do capitalismo e da tecnociência é a busca de "mais e mais", de um crescimento sem fim orientado para o acúmulo de riqueza que, por sua vez, aprimora o conhecimento técnico para gerar ainda mais riqueza. Essa lógica, insustentável e suicida como uma bomba-relógio, coloca em marcha uma sequência infinita de transformações e operações que (além de exaurir os recursos naturais do planeta) leva a humanidade a uma permanente frustração. Para o filósofo francês Jean-François Lyotard, lido por Ricardo Fabbrini (2017, p.58), essa desmedida é o "fato essencial da pósmodernidade", que encontraria uma forma de representação através do excesso de beleza, ligada ao sublime. Mas, se no projeto moderno o sublime era visto como a face estética de um projeto utópico de redenção, através da racionalidade e do triunfo da civilização e da técnica, agora ele mostra seu lado negativo, opressor. 


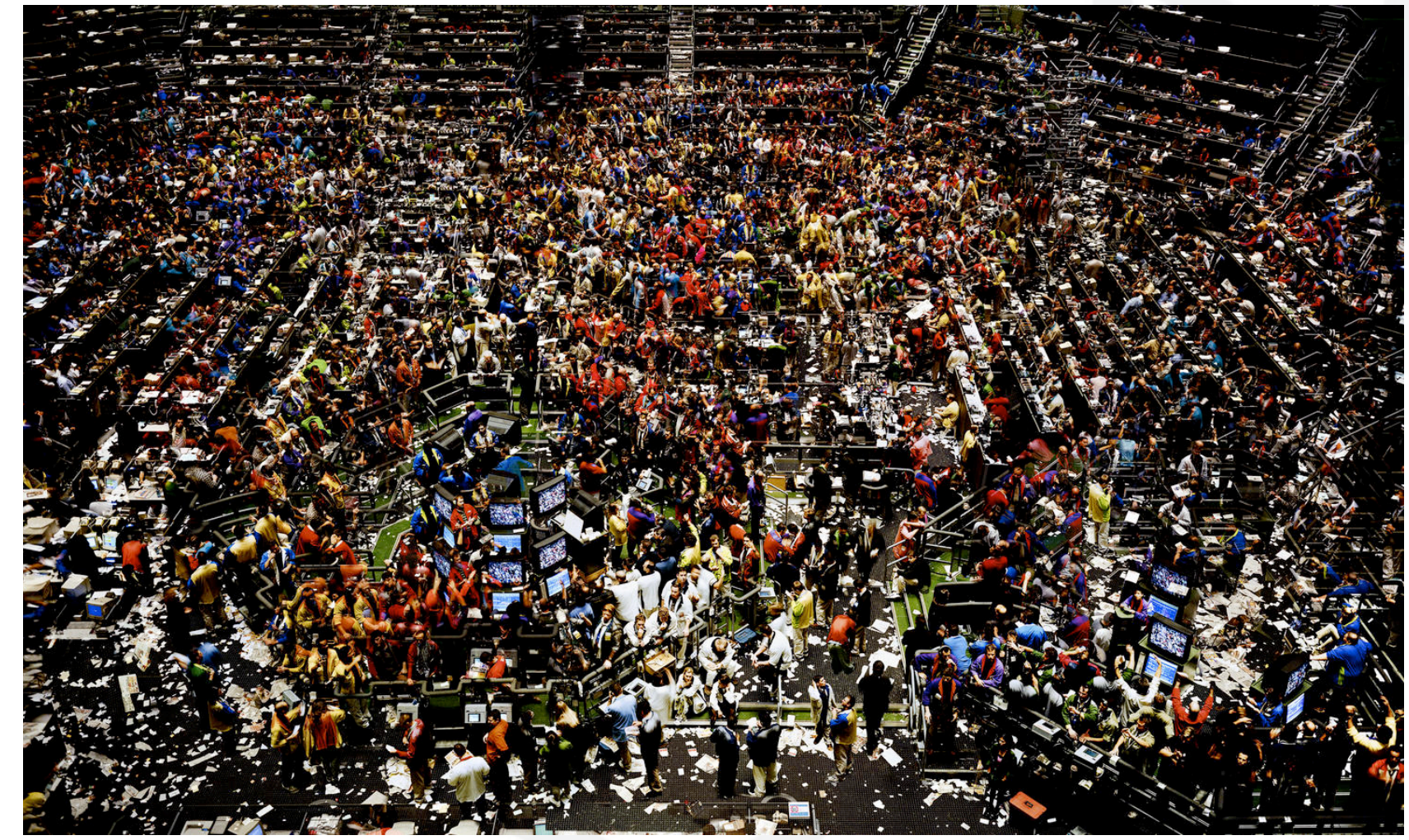

Figura 5: Andreas Gursky. Chicago Board of Trade II (1999). Fonte: Site do autor.

Nesse sentido não seriam as imagens de Andreas Gursky, com todo seu hiperrealismo digital, uma tentativa de representar o irrepresentável mundo contemporâneo submetido aos excessos do capitalismo financeiro - um mundo saturado de imagens, onde mídia e ambiente se fundem? Ao eleger como tema justamente o "espaço mundial do capitalismo multinacional" chamado de "objeto fundamental da pós-modernidade" por Fredric Jameson (2000, p. 79) -, não seria seu trabalho uma legítima estratégia artística de representação dessa realidade, uma tentativa de mapear cognitivamente as forças do capital?

É incômodo pensar que esta resposta seja dada por um fotógrafo plenamente inserido no circuito comercial e avesso às interpretações políticas de sua 
obra $^{12}$. De fato, há um problema. Diferentemente do sublime lírico que desorienta o ser humano e carrega grande carga de violência (logo, potencialmente perigosa e disruptiva), a estética de Gursky é domesticada por um "sublime formalizado" com sua alta resolução, sua estética publicitária e pela manipulação digital que "limpa" as imperfeições indesejadas. Ao invés de um ambiente aterrador, violento e misterioso de uma tormenta em alto mar, temos o ambiente "hiperespacial" de um hotel genérico (Atlanta, 1996), uma loja asséptica da grife Prada (Prada I, 1996) ou um show da Madonna (Madonna I, 2001). O perigo é que tal visão, com toda sua sofisticação visual, estética publicitária e encantamento, pode fetichizar e naturalizar esse mundo injusto e cruel que procura representar. Basta imaginarmos essas imensas fotografias nas grandes galerias de Londres, Nova York e Frankfurt, convertidas em fundo cenográfico de um espetáculo ostentatório. Ali, são vendidas por alguns milhões de dólares para bilionários russos e príncipes sauditas ao som do tilintar das melhores taças de champanhe.

\section{REFERÊNCIAS BIBLIOGRÁFICAS}

\section{Bibliografia citada}

BENJAMIN, Walter. Obras escolhidas I: magia e técnica, arte e política. São Paulo: Brasiliense, 1985.

BAUDRILLARD, Jean. As estratégias fatais. Rio de Janeiro: Rocco, 1996.

COTTON, Charllotte. A fotografia como arte contemporânea. São Paulo: Martins Fontes; 2010.

FABBRINI, Ricardo Nascimento. Estética e crítica da arte em Jean-François Lyotard. O Que nos Faz Pensar: Cadernos do Departamento de Filosofia da Puc-Rio, Rio de Janeiro, v. 26, n. 40, pp. 47-77, 2017.

\footnotetext{
${ }^{12}$ Gursky ganhou notoriedade depois que a obra 99 Cent II Diptychon (2001) alcançou o preço de 3.34 milhões de dólares em 2007 tornando-se, na época, a mais cara fotografia já vendida.
} 
JAMESON, Fredric. Pós-modernismo: a lógica cultural do capitalismo tardio. São Paulo: Ática, 2000.

LOENGARD, John. Celebrating the negative. Nova York: Arcade; 1994.

NAYERI, Farah. Andreas Gursky is taking photos of things that do not exist. The New York Times. Nova York, p. C2. 29 jan. 2018.

SAFATLE, Vladimir. Do sublime capitalista e das ruínas. Revista Cult, São Paulo, p.51-54, 2007.

WISNIK, Guilherme. Dentro do nevoeiro: arquitetura, arte e tecnologia contemporâneas. São Paulo: Ubu, 2018.

\section{LISTA DE FOTOS}

Figura 1 - Tuca Vieira, 2020. Negativo da série “Fotografia de Rua" (2008). pág.: 80

Figura 2 - Apollo 17. The blue marble (1972) pág.: 82

Figura 3 - Andreas Gursky. Paris, Montparnasse (1993) pág.: 86

Figura 4 - NASA. The blue marble (2012) pág.: 91

Figura 5 - Andreas Gursky. Chicago Board of Trade II (1999) pág.: 94 